\title{
Article \\ Plasticity in Intrinsic Excitability of Hypothalamic Magnocellular Neurosecretory Neurons in Late-Pregnant and Lactating Rats
}

\author{
Michael R. Perkinson 1,2,3, Rachael A. Augustine 1,2,3,4, Gregory T. Bouwer 1,2,3, Emily F. Brown 1,2,3,4 , \\ Isaiah Cheong 1,2,3,4, Alexander J. Seymour 1,2,3, Martin Fronius ${ }^{3,4}$ and Colin H. Brown 1,2,3,*(D) \\ 1 Brain Health Research Centre, University of Otago, Dunedin 9054, New Zealand; \\ permi016@student.otago.ac.nz (M.R.P.); rachael.augustine@otago.ac.nz (R.A.A.); \\ gregory.bouwer@otago.ac.nz (G.T.B.); emily.brown@postgrad.otago.ac.nz (E.F.B.); \\ isaiah.cheong@otago.ac.nz (I.C.); xander.seymour@otago.ac.nz (A.J.S.) \\ 2 Centre for Neuroendocrinology, University of Otago, Dunedin 9054, New Zealand \\ 3 Department of Physiology, School of Biomedical Sciences, University of Otago, P.O. Box 56, \\ Dunedin 9054, New Zealand; martin.fronius@otago.ac.nz \\ 4 HeartOtago, University of Otago, Dunedin 9054, New Zealand \\ * Correspondence: colin.brown@otago.ac.nz; Tel.: +64-3-479-7354
}

Citation: Perkinson, M.R.;

Augustine, R.A.; Bouwer, G.T.; Brown E.F.; Cheong, I.; Seymour, A.J.; Fronius, M.; Brown, C.H. Plasticity in Intrinsic Excitability of Hypothalamic Magnocellular Neurosecretory Neurons in Late-Pregnant and Lactating Rats. Int. J. Mol. Sci. 2021, 22, 7140. https://doi.org/10.3390/ ijms 22137140

Academic Editor:

Kerstin Uvnäs-Moberg

Received: 2 June 2021

Accepted: 25 June 2021

Published: 1 July 2021

Publisher's Note: MDPI stays neutral with regard to jurisdictional claims in published maps and institutional affiliations.

Copyright: (c) 2021 by the authors Licensee MDPI, Basel, Switzerland. This article is an open access article distributed under the terms and conditions of the Creative Commons Attribution (CC BY) license (https:// creativecommons.org/licenses/by/ $4.0 /)$
Abstract: Oxytocin and vasopressin secretion from the posterior pituitary gland are required for normal pregnancy and lactation. Oxytocin secretion is relatively low and constant under basal conditions but becomes pulsatile during birth and lactation to stimulate episodic contraction of the uterus for delivery of the fetus and milk ejection during suckling. Vasopressin secretion is maintained in pregnancy and lactation despite reduced osmolality (the principal stimulus for vasopressin secretion) to increase water retention to cope with the cardiovascular demands of pregnancy and lactation. Oxytocin and vasopressin secretion are determined by the action potential (spike) firing of magnocellular neurosecretory neurons of the hypothalamic supraoptic and paraventricular nuclei. In addition to synaptic input activity, spike firing depends on intrinsic excitability conferred by the suite of channels expressed by the neurons. Therefore, we analysed oxytocin and vasopressin neuron activity in anaesthetised non-pregnant, late-pregnant, and lactating rats to test the hypothesis that intrinsic excitability of oxytocin and vasopressin neurons is increased in late pregnancy and lactation to promote oxytocin and vasopressin secretion required for successful pregnancy and lactation. Hazard analysis of spike firing revealed a higher incidence of post-spike hyperexcitability immediately following each spike in oxytocin neurons, but not in vasopressin neurons, in late pregnancy and lactation, which is expected to facilitate high frequency firing during bursts. Despite lower osmolality in late-pregnant and lactating rats, vasopressin neuron activity was not different between non-pregnant, late-pregnant, and lactating rats, and blockade of osmosensitive $\triangle \mathrm{N}$-TRPV1 channels inhibited vasopressin neurons to a similar extent in non-pregnant, late-pregnant, and lactating rats. Furthermore, supraoptic nucleus $\triangle \mathrm{N}$-TRPV1 mRNA expression was not different between non-pregnant and late-pregnant rats, suggesting that sustained activity of $\triangle \mathrm{N}-\mathrm{TRPV} 1$ channels might maintain vasopressin neuron activity to increase water retention during pregnancy and lactation.

Keywords: oxytocin; vasopressin; pregnancy; lactation; supraoptic nucleus; transient receptor potential vanilloid channel

\section{Introduction}

Secretion of the posterior pituitary hormones, oxytocin, and vasopressin (the antidiuretic hormone) is required for successful pregnancy and lactation. Oxytocin is required for normal delivery during birth and is essential for milk-ejection during lactation [1], while vasopressin increases water retention during pregnancy for adequate placental blood 
supply [2]. Vasopressin secretion is principally stimulated by body fluid osmolality to promote renal water reabsorption, and therefore lowered osmolality normally decreases vasopressin secretion [3]. However, the osmotic set-point for vasopressin secretion is decreased during pregnancy to increase renal water reabsorption despite lowered osmolality in order to support blood volume expansion to cope with the cardiovascular demands of the developing fetus $[4,5]$.

Oxytocin and vasopressin are synthesised by magnocellular neurosecretory neurons of the hypothalamic supraoptic and paraventricular nuclei that each project a single axon to the posterior pituitary gland where hormone secretion into the circulation is triggered by action potential (spike) firing [1]. Oxytocin neurons typically fire spikes in a slow continuous pattern [1] to maintain relatively constant oxytocin concentrations [6]. However, oxytocin neurons fire short high frequency bursts every 5-10 min during birth and suckling [7-9] to secrete large pulses of oxytocin that induce rhythmic uterine contraction during birth and episodic milk ejection during suckling.

While afferent inputs are necessary for osmotic activation of vasopressin neurons, direct osmotically-induced depolarisation is also necessary to increase the excitability of the neurons for spike firing $[10,11]$. Osmotically-induced depolarisation results from activation of N-terminal-truncated TRPV1 ( $\triangle \mathrm{N}$-TRPV1) channels [12] that are mechanically gated by osmotically-induced cell shrinkage $[13,14]$.

In addition to afferent inputs and baseline membrane potential, the excitability of magnocellular neurons depends on post-spike potentials (afterpotentials); the fast, medium, and slow afterhyperpolarisations (fAHP, mAHP, and sAHP) [15-17] shift membrane potential away from action potential threshold after each action potential to transiently reduce the probability of the next action potential firing (post-spike refractoriness), while the fast and slow afterdepolarisations (fADP and sADP) [18-20] shift membrane potential towards threshold to transiently increase the probability of the next action potential firing (post-spike hyperexcitability).

Here, we analysed basal spike patterning in oxytocin and vasopressin neurons of nonpregnant, late-pregnant, and lactating rats to determine whether their post-spike excitability is increased in pregnancy and lactation. In addition, we used pharmacological blockade of $\triangle \mathrm{N}$-TRPV1 channels to determine whether intrinsic osmosensitivity of vasopressin neurons is increased in late pregnancy and lactation.

\section{Results}

2.1. Basal Firing Rate of Oxytocin and Vasopressin Neurons in Non-Pregnant, Late-Pregnant, and Lactating Rats

Spontaneous activity was analysed from the first $10 \mathrm{~min}$ of 94 recordings from oxytocin neurons and 204 recordings from vasopressin neurons in 76 non-pregnant rats, 74 latepregnant rats, and 35 lactating rats. There was no effect of reproductive status on the basal firing rate of oxytocin neurons (one-way ANOVA on ranks; $H=0.35, p=0.84$ ) or vasopressin neurons $(H=0.56, p=0.76$; Figure 1$)$. 
Oxytocin

Vasopressin
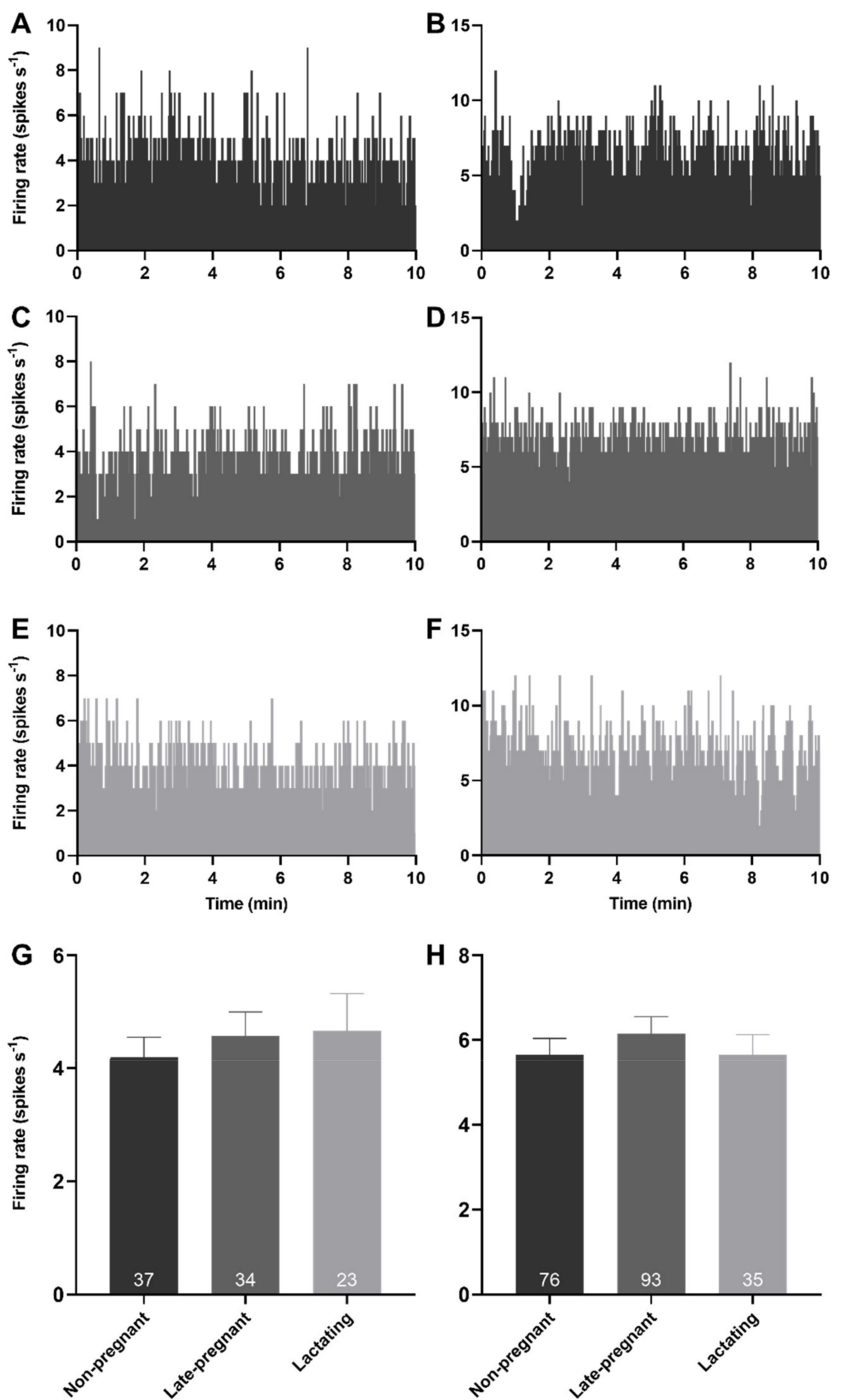

Figure 1. Basal firing rates of oxytocin and vasopressin neurons were not affected by reproductive status. (A-F) Example ratemeter recordings of oxytocin neuron $(\mathbf{A}, \mathbf{C}, \mathbf{E})$ and vasopressin neuron (B,D,F) firing rate (in $1 \mathrm{~s}$ bins) from urethane-anaesthetised non-pregnant (A,B), late-pregnant (C,D), and lactating $(\mathbf{E}, \mathbf{F})$ rats. $(\mathbf{G}, \mathbf{H})$. Mean ( \pm standard error of mean $(\mathrm{SEM}))$ spontaneous oxytocin neuron (G) and vasopressin (non-phasic and phasic) neuron $(\mathbf{H})$ firing rates (averaged over $10 \mathrm{~min}$ ) in non-pregnant, late-pregnant, and lactating rats. There was no effect of reproductive status on the basal firing rate of oxytocin neurons (one-way ANOVA on ranks; $H=0.35, p=0.84$ ) or vasopressin neurons $(H=0.56, p=0.76)$. 


\subsection{Phasic Activity of Vasopressin Neurons in Non-Pregnant, Late-Pregnant, and Lactating Rats}

Spontaneous phasic activity was evident in 54 vasopressin neurons. There was no effect of reproductive status on the overall firing rate $(H=3.52, p=0.17)$, intraburst firing rate $(H=2.31, p=0.32)$, burst duration $(H=0.26, p=0.88)$, or interburst interval of phasic neurons $(H=4.72, p=0.09$; Figure 2$)$.
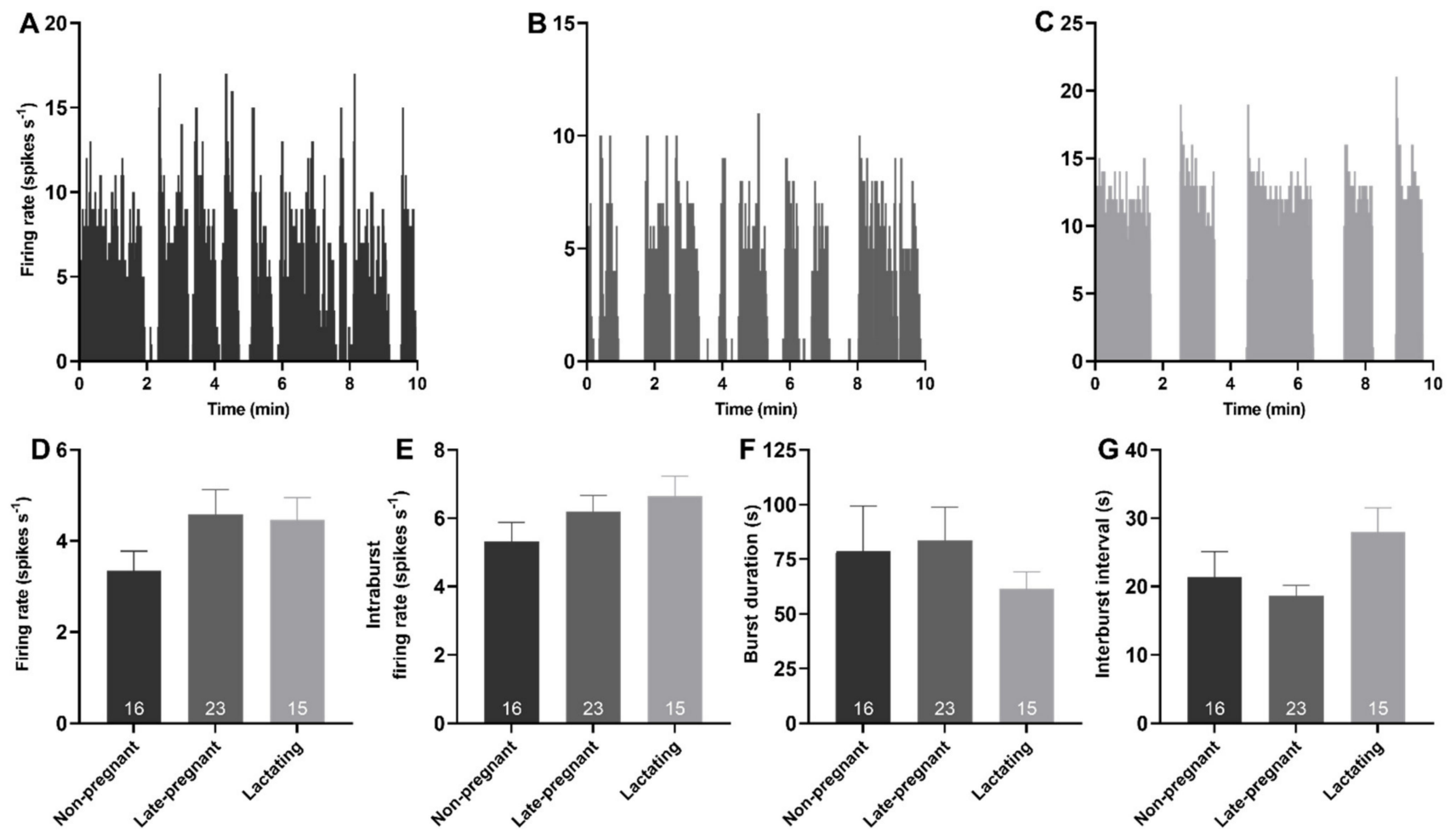

Figure 2. Phasic activity of vasopressin neurons was not affected by reproductive status. (A-C). Example ratemeter recordings of spontaneous phasic activity in vasopressin neurons (in $1 \mathrm{~s}$ bins) from urethane-anaesthetised non-pregnant (A), late-pregnant (B), and lactating $(\mathbf{C})$ rats. $(\mathbf{D}-\mathbf{G})$. Mean $( \pm S E M)$ phasic neuron firing rate $(\mathbf{D})$, intraburst firing rate $(\mathbf{E})$, burst duration $(\mathbf{F})$, and interburst interval $(\mathbf{G})$ in non-pregnant, late-pregnant, and lactating rats. There was no effect of reproductive status on the firing rate $(H=3.52, p=0.17)$, intraburst firing rate $(H=2.31, p=0.32)$, burst duration $(H=0.26$, $p=0.88)$, or interburst interval of phasic neurons $(H=4.72, p=0.09)$.

\subsection{Post-Spike Excitability in Oxytocin and Vasopressin Neurons in Non-Pregnant, Late-Pregnant, and Lactating Rats}

Hazard functions were generated to determine whether post-spike excitability of oxytocin and vasopressin neurons was different between non-pregnant, late-pregnant, and lactating rats. There was no effect of reproductive status on peak early hazard $(H=1.00$, $p=0.61$; one-way ANOVA on ranks), mean late hazard $(H=0.09, p=0.95)$, or hazard ratio $(H=1.69, p=0.43)$ of oxytocin neurons (Figure 3$)$. Nevertheless, oxytocin neurons in late-pregnant and lactating rats had a higher incidence of hazard ratios that reached the threshold to be classified as elevated post-spike hyperexcitability $\left(\chi^{2}=7.07, p=0.03\right.$; Figure 3F).

There was no effect of reproductive status on the peak early hazard $(H=0.82, p=0.66)$, mean late hazard $(H=1.81, p=0.40)$, or hazard ratio $(H=4.72, p=0.09)$ of all (non-phasic and phasic) vasopressin neurons (Figure 4). Similarly, there was no effect of reproductive status on the peak early hazard $(H=0.17, p=0.92)$, mean late hazard $(H=4.27, p=0.12)$, or hazard ratio $(H=0.41, p=0.82)$ of phasic vasopressin neurons (Figure S2). There was no difference in the incidence of hazard ratios that reached the threshold to be classified 
as elevated post-spike hyperexcitability in vasopressin neurons in non-pregnant, latepregnant, and lactating rats $\left(\chi^{2}=2.38, p=0.30\right.$; Figure $\left.4 \mathrm{~F}\right)$.
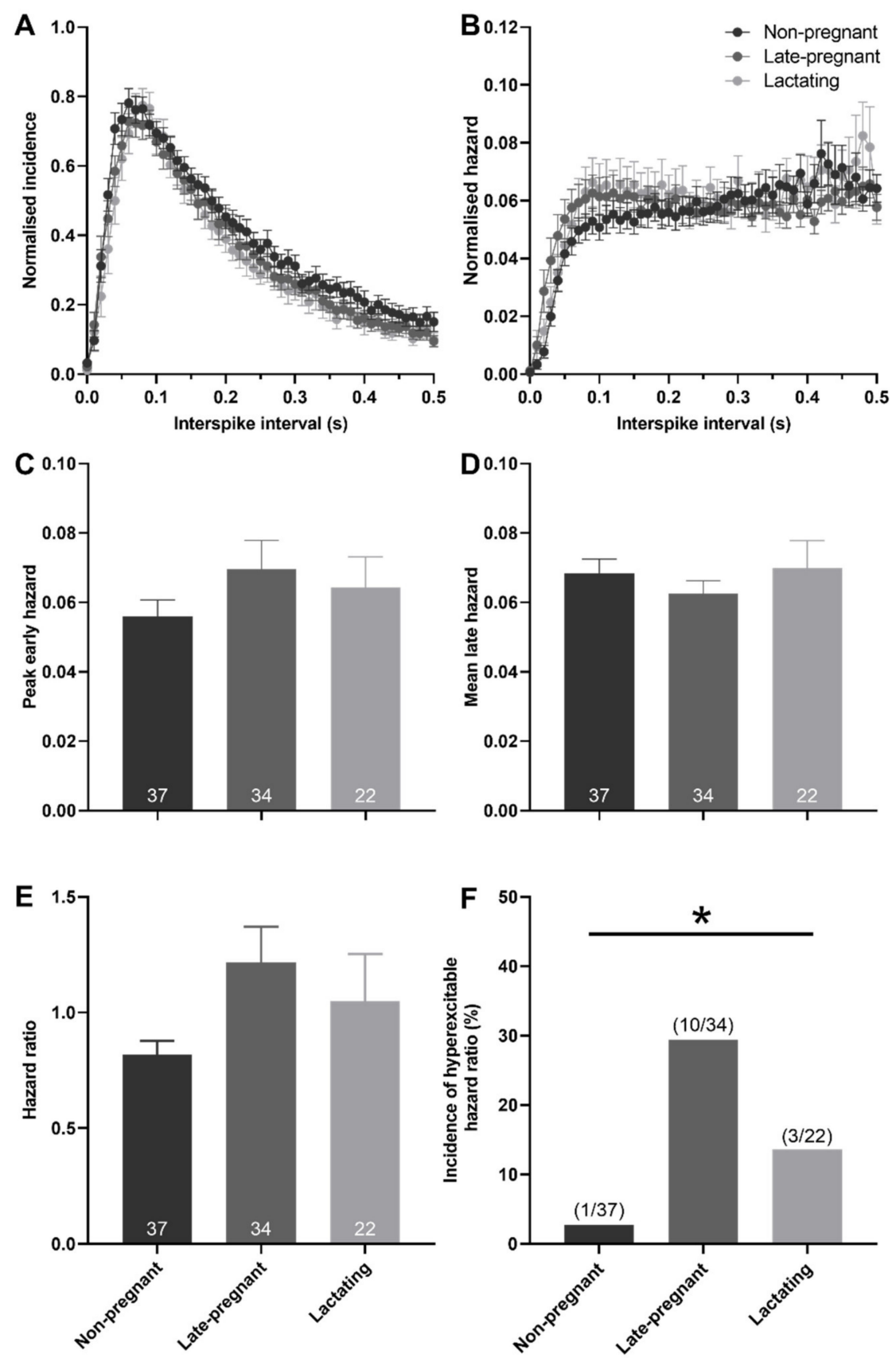

Figure 3. Post-spike excitability in oxytocin neurons in non-pregnant, late-pregnant, and lactating rats. (A) Mean normalised interspike intervals $( \pm S E M)$ of basal activity in oxytocin neurons from non-pregnant, late-pregnant, and lactating rats. (B) Mean ( \pm SEM) normalised hazard functions from the same neurons in (A). (C-E) Mean ( \pm SEM) peak early hazard (C), late hazard (D), and peak early/mean late hazard ratio (E) in oxytocin neurons from non-pregnant, late-pregnant, and lactating rats. There was no effect of reproductive status on peak early hazard $(H=1.00, p=0.61$; one-way ANOVA on ranks), mean late hazard $(H=0.09, p=0.95)$, or hazard ratio $(H=1.69, p=0.43)$ of oxytocin neurons. (F) Proportion of oxytocin neurons with post-spike hyperexcitability in nonpregnant, late-pregnant, and lactating rats. The incidence of post-spike hyperexcitability was different between oxytocin neurons from non-pregnant, late-pregnant, and lactating rats $\left(\chi^{2}=7.07,{ }^{*} p=0.03\right)$. 

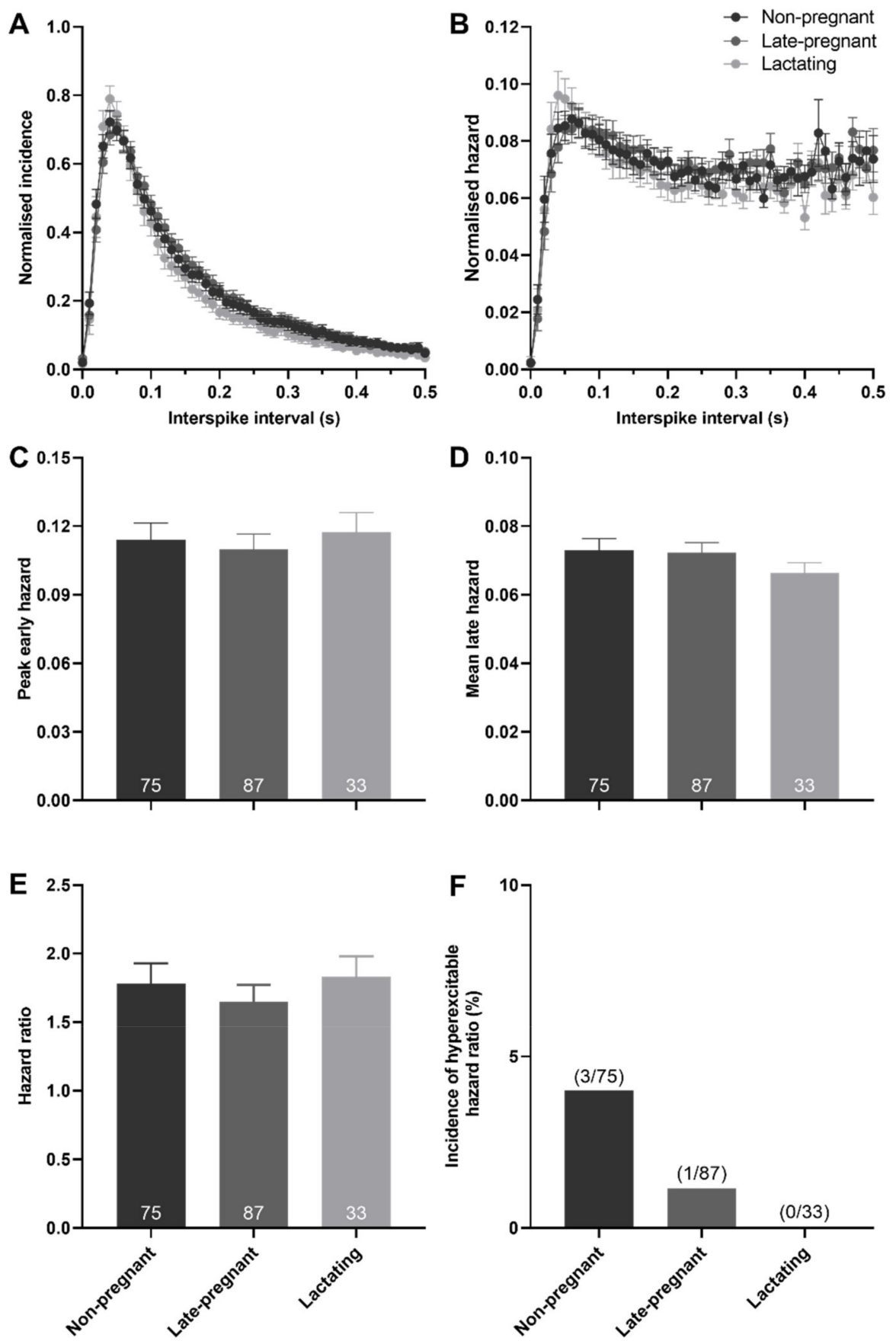

Figure 4. Post-spike excitability in vasopressin neurons in non-pregnant, late-pregnant, and lactating rats. (A) Mean $( \pm \mathrm{SEM})$ normalised interspike intervals of basal activity in vasopressin neurons from non-pregnant, late-pregnant, and lactating rats. (B) Mean $( \pm S E M)$ normalised hazard functions from the same neurons in (A). (C-E) Mean ( \pm SEM) peak early hazard $(\mathbf{C})$, late hazard $(\mathbf{D})$, and peak early/mean late hazard ratio (E) in vasopressin neurons from non-pregnant, late-pregnant, and lactating rats. There was no effect of reproductive status on the peak early hazard $(H=0.82, p=0.66)$, mean late hazard $(H=1.81, p=0.40)$, or hazard ratio $(H=4.72, p=0.09)$ in vasopressin neurons. $(\mathbf{F})$ Proportion of vasopressin neurons with post-spike hyperexcitability in non-pregnant, late-pregnant, and lactating rats. The incidence of post-spike hyperexcitability was not different between vasopressin neurons from non-pregnant, late-pregnant, and lactating rats $\left(\chi^{2}=2.38, p=0.30\right)$. 


\subsection{Variability of Spike Firing in Oxytocin and Vasopressin Neurons in Non-Pregnant, \\ Late-Pregnant, and Lactating Rats}

The CV was calculated to determine whether the higher incidence of post-spike hyperexcitability in oxytocin neurons of late-pregnant and lactating rats was associated with increased variability of spike firing. While there was no effect of reproductive status on the $\mathrm{CV}$ of oxytocin neurons $(H=0.76, p=0.69)$, vasopressin neurons $(H=5.43, p=0.07)$, or phasic vasopressin neurons $(H=2.73, p=0.25$; Figure S3), there was a significant correlation between the $\mathrm{CV}$ and hazard ratio for oxytocin neurons (Spearman rank order correlation coefficient, $r=0.24, p=0.03)$, vasopressin neurons $(r=0.49, p<0.001)$, and phasic vasopressin neurons $(r=0.43, p=0.002$; Figure 5).
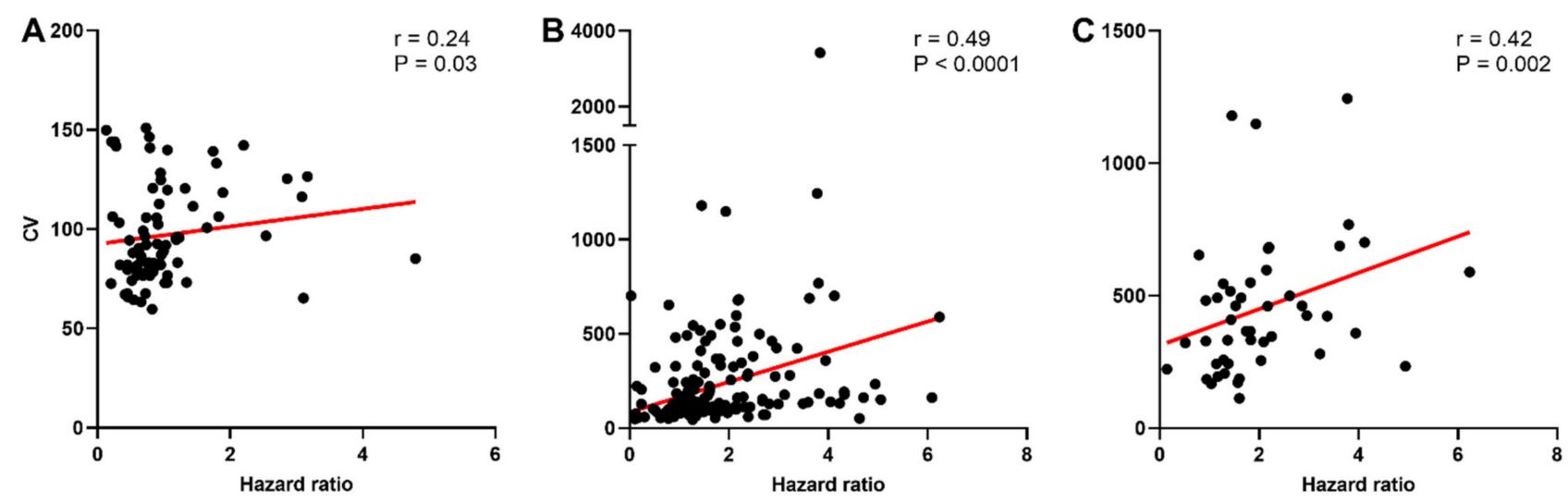

Figure 5. Variability of spike firing in oxytocin and vasopressin neurons in non-pregnant, late-pregnant, and lactating rats. (A-C) Scatter plots of the coefficient of variation of inter-spike interval (CV) against peak early/mean late hazard ratio in oxytocin neurons (A), vasopressin neurons (B), and phasic vasopressin neurons (C) from non-pregnant, late-pregnant, and lactating rats. There was a significant correlation between the $\mathrm{CV}$ and hazard ratio for oxytocin neurons (Spearman rank order correlation coefficient, $r=0.24, p=0.03)$, for vasopressin neurons $(r=0.49, p<0.001)$, and for phasic vasopressin neurons $(r=0.43, p=0.002)$. Regression lines are shown for illustrative purpose only.

\subsection{Ruthenium Red Effects on Oxytocin and Vasopressin Neuron Activity in Non-Pregnant,} Late-Pregnant, and Lactating Rats

As expected, plasma osmolality was affected by reproductive status $(H=20.0, p<0.001)$ with lower osmolality in late-pregnant rats ( $p<0.001$, Dunn's post hoc test) and lactating rats $(p=0.04)$ than in non-pregnant rats. Despite lower osmolality in late-pregnant and lactating rats, microdialysis administration of ruthenium red into the supraoptic nucleus reduced the firing rate of vasopressin neurons to a similar extent in non-pregnant, latepregnant, and lactating rats $\left(\mathrm{F}_{2,28}=0.69, p=0.51\right.$ for the main effect of REPRODUCTIVE STATUS; $\mathrm{F}_{6,28}=5.94, p<0.001$ for the main effect of TIME; $\mathrm{F}_{12,32}=0.29, p=0.99$ for the interaction between REPRODUCTIVE STATUS and TIME, two-way repeated measures ANOVA; Figure 6). There was no effect of ruthenium red on the peak early hazard $\left(\mathrm{F}_{1,28}=1.70, p=0.20\right)$, mean late hazard $\left(\mathrm{F}_{1,26}=0.37, p=0.85\right)$, or hazard ratio $\left(\mathrm{F}_{1,26}=0.21\right.$, $p=0.81$ ) of vasopressin neurons and no interaction of ruthenium red with reproductive status (Figure 6).

By contrast to vasopressin neurons, oxytocin neuron activity was not affected by ruthenium red in non-pregnant or late-pregnant rats $\left(\mathrm{F}_{1,9}=0.03, p=0.87\right.$ for the main effect of REPRODUCTIVE STATUS; $\mathrm{F}_{6,9}=1.10, p=0.37$ for the main effect of TIME; $\mathrm{F}_{6,9}=1.00$, $p=0.41$ for the interaction, two-way repeated measures ANOVA; Figure 7). There was no effect of ruthenium red on the peak early hazard $\left(\mathrm{F}_{1,9}=0.58, p=0.46\right)$, mean late hazard $\left(\mathrm{F}_{1,9}=1.97, p=0.19\right)$, or hazard ratio $\left(\mathrm{F}_{1,9}=0.09, p=0.77\right)$ of oxytocin neurons and no interaction of ruthenium red with reproductive status (Figure 7). 

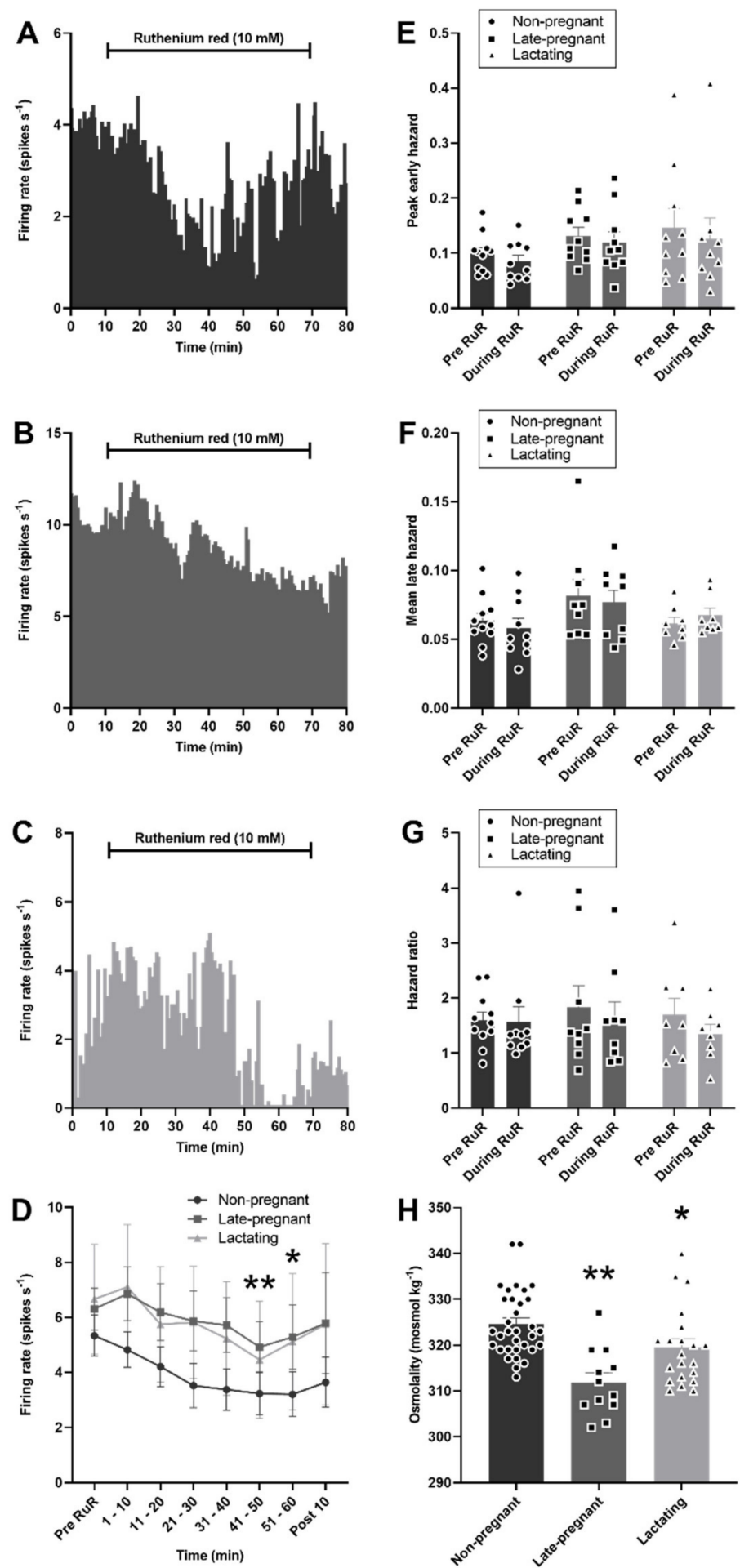

Figure 6. Ruthenium red inhibited vasopressin neuron activity in non-pregnant, late-pregnant, and lactating rats. (A-C) Ratemeter recordings (in $30 \mathrm{~s}$ bins) of the firing rates of vasopressin neurons in non-pregnant (A), late-pregnant (B), and lactating (C) rats before and during microdialysis administration of ruthenium red (RuR; $10 \mathrm{mM}$ ). (D) Mean firing rate (in $10 \mathrm{~min}$ bins $\pm \mathrm{SEM}$ ) of vasopressin neurons in non-pregnant, late-pregnant, and lactating rats before and during microdialysis administration of ruthenium red $(10 \mathrm{mM})$. Ruthenium red induced a similar reduction in the firing rate of vasopressin neurons in non-pregnant, late-pregnant, and lactating rats (REPRODUCTIVE STATUS: $\mathrm{F}_{2,28}=0.69, p=0.51$; TIME: $\mathrm{F}_{6,28}=5.94, p<0.001$; interaction between REPRODUCTIVE STATUS and TIME: $\mathrm{F}_{12,32}=0.29, p=0.99$, two-way repeated measures ANOVA). ${ }^{*} p<0.05$ and ${ }^{* *} p<0.01$ compared to pre-RuR within TIME, Holm-Sidak post hoc tests. (E-G) Mean $( \pm$ SEM) peak early 
hazard (E), late hazard (F), and peak early/mean late hazard ratio (G) in vasopressin neurons from non-pregnant, late-pregnant, and lactating rats. There was no effect of REPRODUCTUVE STATUS or TIME on the peak early hazard $\left(\mathrm{F}_{1,28}=1.70, p=0.20\right)$, mean late hazard $\left(\mathrm{F}_{1,26}=0.37, p=0.85\right)$, or hazard ratio $\left(\mathrm{F}_{1,26}=0.21, p=0.81\right)$ of vasopressin neurons during ruthenium red administration, and no interaction between REPRODUCTUVE STATUS and TIME. (H). Mean ( \pm SEM) plasma osmolality in non-pregnant, late-pregnant, and lactating rats. Plasma osmolality was affected by reproductive status $(H=20.0, p<0.001) .{ }^{*} p<0.05$ and ${ }^{* *} p<0.01$. Dunn's post hoc tests compared to non-pregnant rats.
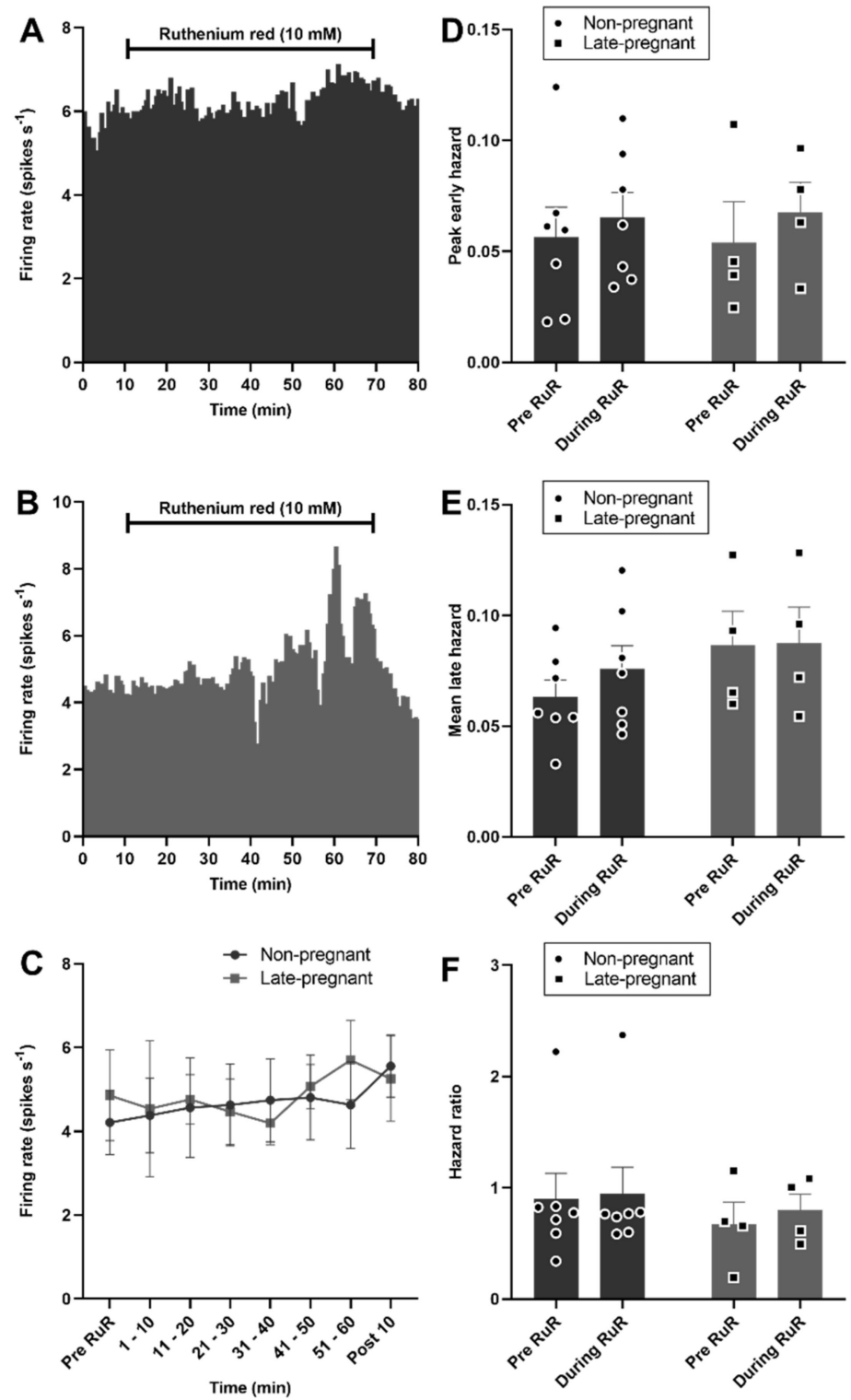

Figure 7. Ruthenium red did not affect oxytocin neuron activity in non-pregnant and late-pregnant rats. (A,B) Ratemeter recordings (in $30 \mathrm{~s}$ bins) of the firing rates of oxytocin neurons in non-pregnant (A) and late-pregnant (B) rats before and during microdialysis administration of ruthenium red (RuR; $10 \mathrm{mM}$ ). (C) Mean firing rate (in $10 \mathrm{~min}$ bins \pm SEM) of oxytocin neurons in non-pregnant and late-pregnant rats before and during microdialysis administration of ruthenium red (10 $\mathrm{mM})$. Oxytocin neuron activity was not affected by ruthenium red in non-pregnant or late-pregnant rats (REPRODUCTIVE STATUS: $\mathrm{F}_{1,9}=0.03, p=0.87$; TIME: $\mathrm{F}_{6,9}=1.10, p=0.37$; interaction between 
REPRODUCTIVE STATUS and TIME: $\mathrm{F}_{6,9}=1.00, p=0.41$, two-way repeated measures ANOVA). (D-F) Mean ( \pm SEM) peak early hazard (D), late hazard (E), and peak early/mean late hazard ratio (F) in oxytocin neurons from non-pregnant, late-pregnant, and lactating rats. There was no effect of REPRODUCTIVE STATUS or TIME on the peak early hazard $\left(\mathrm{F}_{1,9}=0.58, p=0.46\right)$, mean late hazard $\left(\mathrm{F}_{1,9}=1.97, p=0.19\right)$, or hazard ratio $\left(\mathrm{F}_{1,9}=0.09, p=0.77\right)$ of oxytocin neurons during ruthenium red administration, and no interaction between REPRODUCTUVE STATUS and TIME.

2.6. $\triangle N$-TRPV1 $m R N A$ and Vasopressin mRNA Expression in the Supraoptic Nucleus of Non-Pregnant and Late-Pregnant Rats

Labelling of $\triangle \mathrm{N}$-TRPV1 mRNA and vasopressin mRNA was most prominent within the supraoptic nucleus (Figure S1). $\triangle \mathrm{N}$-TRPV1 mRNA was evident as punctate labelling whereas vasopressin mRNA labelling was evident throughout the cytoplasm in the cell bodies. There was no difference in $\triangle \mathrm{N}$-TRPV1 mRNA expression $(p=0.66$, unpaired $t$-test) or vasopressin mRNA expression $(p=0.71)$ between non-pregnant and late-pregnant rats. Co-expression of $\triangle \mathrm{N}$-TRPV1 mRNA with vasopressin mRNA was not different between non-pregnant and late-pregnant rats $(p=0.41$; Figure 8$)$. In addition, co-expression of vasopressin mRNA with $\triangle \mathrm{N}$-TRPV1 mRNA was not different between non-pregnant $(50.9 \pm 2.5 \%)$ and late-pregnant rats $(46.2 \pm 0.3 \% ; p=0.63$, unpaired $t$-test).
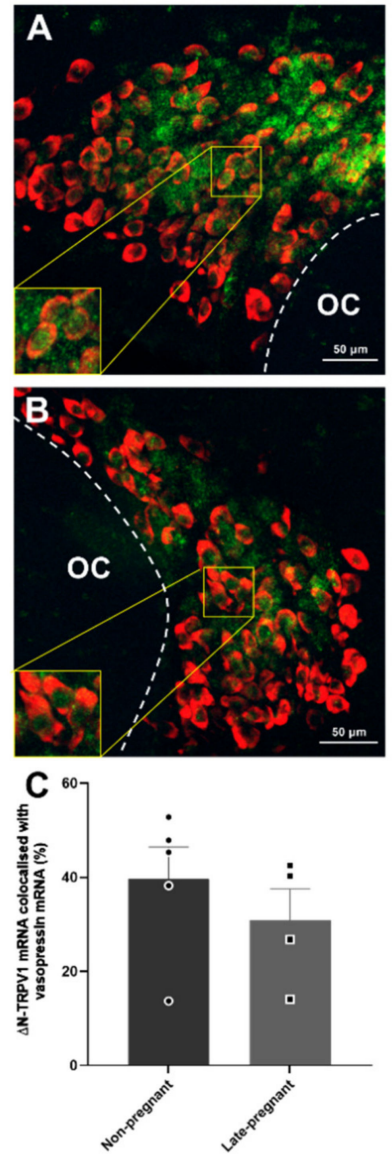

Figure 8. Vasopressin mRNA and $\triangle \mathrm{N}-\mathrm{TRPV} 1 \mathrm{mRNA}$ expression in the supraoptic nucleus of nonpregnant and late-pregnant rats. (A,B) Example compressed Z-stacks of vasopressin mRNA (red) and $\triangle \mathrm{N}$-TRPV1 mRNA (green) labelling in the supraoptic nucleus of non-pregnant (A) and late-pregnant (B) rats. OC: optic chiasm. (C) Mean levels of $\triangle N$-TRPV1 mRNA and vasopressin mRNA co-labelling in the supraoptic nucleus of non-pregnant and late-pregnant rats. There was no difference in $\Delta \mathrm{N}$ TRPV1mRNA expression ( $p=0.66$, unpaired $t$-test), vasopressin mRNA expression $(p=0.71)$, or co-expression of $\triangle \mathrm{N}-\mathrm{TRPV} 1 \mathrm{mRNA}$ and vasopressin mRNA between non-pregnant and late-pregnant rats $(p=0.41)$. 


\section{Discussion}

Here, we found that basal firing rate was not different between oxytocin neurons in non-pregnant, late-pregnant, and lactating rats or between vasopressin neurons in non-pregnant, late-pregnant, and lactating rats, consistent with our previous observations [21,22]. Nevertheless, hazard analyses revealed a reorganisation of activity in oxytocin neurons, but not vasopressin neurons, in late-pregnant and lactating rats that favoured the occurrence of short intervals between successive spikes that are necessary to achieve the high firing rates evident during burst firing in birth and lactation. In contrast to oxytocin neurons, the activity of vasopressin neurons in late-pregnant and lactating rats was indistinguishable from that in non-pregnant rats. The maintenance of vasopressin neuron activity in the face of lower plasma osmolality in late pregnancy and lactation appears to involve increased osmosensitivity.

\subsection{Increased Post-Spike Hyperexcitability in Oxytocin Neurons in Late Pregnancy and Lactation}

Hazard functions calculate the probability of the neuron firing a subsequent spike in any given interval following a preceding spike, which reflects post-spike excitability. Changes in the hazard function are inferred to result from changes in membrane potential after each spike and therefore reveal the influence of post-spike potentials on activity patterning [23]. The measures derived from the hazard function to describe post-spike excitability are the peak early hazard, the mean late hazard, and the peak early/mean late hazard ratio. The peak early hazard is inferred to reflect the transient impact of AHPs and ADPs superimposed on baseline excitability [23] but can also be influenced by other transient changes in membrane potential, such as that induced by the transient outward rectifier [24]. The mean late hazard reflects the steady-state excitability of neurons and is inferred to reflect the influence of ongoing synaptic input and underlying membrane potential [23]. The peak early/mean late hazard ratio quantifies the shape of the hazard function by scaling the peak early hazard to the mean late hazard to reveal the relative influence of post-spike potentials and ongoing synaptic input/baseline membrane potential to spike firing.

The oxytocin system undergoes extensive plasticity during pregnancy to prepare for birth and lactation [25] that includes the emergence of an SADP in oxytocin neurons, as well as a shorter mAHP $[26,27]$. The sADP supports burst firing by increasing postspike excitability in vasopressin neurons [28,29]. Hence, the emergence of an sADP in late pregnancy would be expected to increase post-spike excitability of oxytocin neurons to support burst firing essential for normal birth and lactation. While we did not find an overall change in post-spike excitability across all oxytocin neurons, there was clear post-spike hyperexcitability in a similar proportion of oxytocin neurons to those that express a measurable sADP in late pregnancy and lactation [26,27]. Hence, the simplest explanation of increased incidence of post-spike hyperexcitability observed here is an enhanced expression of the SADP by some oxytocin neurons.

Oxytocin neurons generally express fADPs and sADPs under basal conditions, but these are usually masked by the occurrence of a larger mAHP $[16,18]$. Hence, the emergence of post-spike hyperexcitability in oxytocin neurons might reflect a reduced influence of the $\mathrm{mAHP}$ that unmasks the ADPs. The mAHP increases the regularity of oxytocin neuron firing during basal activity [30], and therefore a reduced mAHP could contribute to the increased variability of spike firing $(\mathrm{CV})$ observed here. Increased variability of spike firing is correlated with burst firing in oxytocin neurons [31,32]. The observed positive correlation of $\mathrm{CV}$ with hazard ratio suggests that increased post-spike hyperexcitability might contribute to increased variability of firing. If this is the case, then the oxytocin neurons with higher post-spike hyperexcitability might be those that are most likely to adopt bursting activity [33]. 


\subsection{Increased Excitability in Vasopressin Neurons in Late Pregnancy and Lactation}

Vasopressin secretion is principally stimulated by body fluid osmolality, and therefore lowered osmolality normally decreases vasopressin secretion [3]. However, despite water retention profoundly reducing osmolality in pregnancy and lactation [34], vasopressin levels are unchanged, or even increased in pregnant and lactating humans and rats $[4,5,35-38]$. Consistent with previous observations, the firing rate of vasopressin neurons was not different between non-pregnant, late-pregnant, and lactating rats, despite reduced plasma osmolality. Furthermore, post-spike excitability of vasopressin neurons was not affected by reproductive status, suggesting that the resetting of the osmotic set-point for vasopressin secretion results from a change in overall excitability, rather than a change in post-spike excitability. While overall excitability depends on synaptic input and membrane potential [23], we found that $\triangle \mathrm{N}-\mathrm{TRPV} 1$ inhibition with ruthenium red was equally effective at inhibiting vasopressin neurons in non-pregnant, late-pregnant, and lactating rats without affecting the hazard function. Therefore, it appears likely that the resetting of the osmotic set-point for vasopressin secretion results from maintained activation of $\triangle \mathrm{N}-\mathrm{TRPV} 1$ at the lower osmolality evident in pregnancy and lactation.

The mechanism that might drive any change in $\triangle \mathrm{N}$-TRPV1 function in pregnancy and lactation is unknown. The secretion of various hormones increases over the course of pregnancy, including oestrogen, progesterone, prolactin and relaxin. Neither chronic oestrogen and progesterone infusion [39] nor chronic prolactin infusion [40] affects the osmotic set-point for vasopressin secretion. By contrast, infusion of relaxin promotes water intake in pregnancy and activates vasopressin neurons [41-44], suggesting that increased relaxin secretion might be the primary driver for sustained/increased vasopressin secretion in pregnancy and lactation. While $\triangle \mathrm{N}-\mathrm{TRPV} 1$ can be activated by the peptides, angiotensin II, cholecystokinin, and neurotensin [45], it remains to be determined whether relaxin can activate $\triangle \mathrm{N}$-TRPV1.

$\triangle \mathrm{N}$-TRPV1 contributes to magnocellular neurosecretory neuron activity under basal conditions in vitro [11,46], and our observation that $\triangle \mathrm{N}$-TRPV1 inhibition with ruthenium red reduced vasopressin neuron activity in non-pregnant rats showed for the first time that activation of $\triangle \mathrm{N}$-TRPV1 contributes to the basal activity of vasopressin neurons in vivo. Surprisingly, the activity of oxytocin neurons was not affected by ruthenium red, despite oxytocin neurons being as sensitive to excitation by acute osmotic stimulation as vasopressin neurons [47]. Hence, osmosensitivity of oxytocin neurons appears to be less dependent on $\triangle \mathrm{N}-\mathrm{TRPV} 1$ than for vasopressin neurons.

While ruthenium red inhibits $\triangle \mathrm{N}$-TRPV1 [48], it is a broad-spectrum TRPV inhibitor and has several other well-characterised effects, including reduction of calcium release from the endoplasmic reticulum via ryanodine receptor inhibition [49]. However, ruthenium red is relatively membrane impermeable and is therefore administered directly into cells to study its effects on intracellular calcium release, for example, by inclusion in the micropipette solution during whole-cell patch clamp recording [50]. Intracellular administration of $20 \mu \mathrm{M}$ ruthenium red is required to inhibit the ryanodine receptor in supraoptic nucleus neurons [51], whereas an extracellular concentration of $10 \mu \mathrm{M}$ is required to inhibit $\triangle \mathrm{N}$-TRPV1 channels on supraoptic nucleus neurons in vitro [12]. Here, ruthenium red was administered at $10 \mathrm{mM}$ in the dialysate and microdialysis administration is estimated to deliver a 1000-fold lower drug concentration to the supraoptic nucleus than is contained in the dialysate [52]. Hence, the extracellular concentration of ruthenium red in the supraoptic nucleus in our experiments should be $\approx 10 \mu \mathrm{M}$, which should be sufficient to inhibit $\triangle \mathrm{N}$-TRPV1 channels on the cell surface but not ryanodine receptors on the endoplasmic reticulum. Indeed, inhibition of intracellular calcium release by ruthenium red reduces sADP amplitude in supraoptic nucleus neurons [51], but ruthenium red did not affect the shape of hazard function in the current experiments, confirming that it did not inhibit calcium release from intracellular stores. Rather, ruthenium red caused a generalised reduction in post-spike excitability that would be expected to result from sustained hyperpolarisation of membrane potential [23]. 
Ruthenium red reduced vasopressin neuron activity to the same extent in late-pregnant and lactating rats as in non-pregnant rats, indicating that the $\triangle \mathrm{N}-\mathrm{TRPV} 1$ contribution to basal vasopressin neuron activity is maintained at lower osmolality in late-pregnancy and lactation. $\triangle \mathrm{N}$-TRPV1 mRNA expression was not different between the supraoptic nuclei of non-pregnant and late-pregnant rats, suggesting that $\triangle \mathrm{N}$-TRPV1 synthesis was similar. Hence, increased $\triangle \mathrm{N}$-TRPV1 function might underpin the lower osmotic setpoint for vasopressin secretion that develops in pregnancy [53] and thereby contribute to the expansion of blood volume required to cope with the cardiovascular demands of pregnancy and lactation. TRPV2 and TRPV4 are expressed by vasopressin neurons [54], and each can dimerise with TRPV1 $[55,56]$. We are currently investigating whether TRPV4 dimerisation with $\triangle \mathrm{N}$-TRPV1 might be able to underpin increased osmosensitivity of vasopressin neurons in late pregnancy and lactation.

Approximately half of the $\triangle \mathrm{N}$-TRPV1 mRNA was expressed in vasopressin neurons in non-pregnant and late-pregnant rats. Therefore, the remaining $\triangle N-T R P V 1 \mathrm{mRNA}$ must be expressed by other cells in the supraoptic nucleus, presumably oxytocin neurons. Hence, the expression of $\triangle \mathrm{N}$-TRPV1 mRNA is unlikely to underpin the lower sensitivity of oxytocin neurons to ruthenium red inhibition than vasopressin neurons.

\section{Methods}

\subsection{Animals}

All experimental procedures were approved by the University of Otago Animal Ethics Committee and were carried out in accordance with the New Zealand Animal Welfare Act (1999) and associated guidelines.

Animals were purchased from the University of Otago Animal Facility (Dunedin, New Zealand). Non-pregnant rats were group-housed, while late-pregnant and lactating rats were individually caged from mid-pregnancy onwards, under controlled conditions (12 h light/12 h dark cycle with lights on at $07.00 \mathrm{~h} ; 22 \pm 1^{\circ} \mathrm{C}$ ) with free access to food and water. To generate late-pregnant and lactating rats, we monitored the oestrous cycle daily using vaginal cytology, and the rats were placed overnight in a cage with a male on pro-oestrus. The presence of sperm in the vaginal lavage on the following morning indicated mating had occurred (day 0 of gestation: G0).

Non-pregnant rats were virgin rats that were freely cycling to prevent any potential confounding effects of the oestrous cycle on neuronal activity. Late-pregnant rats were used on G18-21. Lactating rats gave birth on G21 or 22 (day 0 post-partum, PP0) and were used on post-partum days PP07-17.

\subsection{In Vivo Electrophysiology}

The rats were anaesthetised with IP urethane $\left(1.25-1.50 \mathrm{~g} \mathrm{~kg}^{-1}\right.$ ethyl carbamate, Sigma; Merck, Darmstadt, Germany) for extracellular single-unit recording of spike firing. Pups were removed from lactating rats at least $4 \mathrm{~h}$ before experiments commenced. Upon complete cessation of the flexor withdrawal reflex, the left femoral vein was catheterised, and a blood sample removed to measure plasma osmolality by freezing point depression osmometry (Model 3320; Advanced Instruments, Norwood, MA, USA). Plasma osmolality was only measured in rats that received exactly $1.25 \mathrm{~g} \mathrm{~kg}^{-1}$ urethane because urethane is osmotically active. The rats were placed supine in a stereotaxic frame and the pituitary stalk and the right supraoptic nucleus were exposed through the oral and nasal cavities [57].

Following the removal of the meninges overlying the supraoptic nucleus, a U-shaped microdialysis probe [58], permeable to $10 \mathrm{kDa}$ (Spectra/Por RC Hollow Fibers, Spectrum Medical Inc., Houston, TX, USA), was bent to position the loop of the membrane over the ventral surface of the supraoptic nucleus. The supraoptic nucleus was continuously dialysed with artificial cerebrospinal fluid (aCSF; composition in mM: $\mathrm{NaCl} 138, \mathrm{KCl} 3.36$, $\mathrm{NaHCO}_{3}$ 9.52, $\mathrm{Na}_{2} \mathrm{HPO}_{4}$ 0.49, urea 2.16, $\mathrm{CaCl}_{2} 1.26, \mathrm{MgCl}_{2} 1.18$ ) at $3 \mu \mathrm{L} \mathrm{min}^{-1}$.

Extracellular single-unit recordings were made via a glass recording microelectrode (15-40 M 2 ) filled with $0.9 \%$ saline placed through the loop of the microdialysis probe, 
using a Neurolog system connected to a CED 1401 analogue-digital interface (Cambridge Electronic Design, Cambridge, UK) and Spike 2 v8.09 software (Cambridge Electronic Design). Antidromic spikes were evoked in supraoptic nucleus neurons by a side-by-side SNEX-200 stimulating electrode (Science Products GmbH, Hofheim, Germany) placed on the pituitary stalk. The rats were euthanised by IV anaesthetic overdose or IV $3 \mathrm{M} \mathrm{KCl}$ $(0.5 \mathrm{~mL})$ at the end of the experiments.

Neurons that fired less than one spontaneous spike every $10 \mathrm{~s}$ were categorised as silent and were not recorded. Phasic activity was defined as $95 \%$ of spikes begin being portioned into bursts using the following parameters: active periods lasting $\geq 5 \mathrm{~s}$ containing $\geq 20$ spikes and $\geq 5$ s interval between active periods during which there was $\leq 1$ spike every $5 \mathrm{~s}$ [59]. Non-phasic neurons were characterised as oxytocin neurons on the basis of a transient excitation $\geq 0.5$ spikes s${ }^{-1}$ over 5 min following IV injection of $\left(\operatorname{Tyr}\left[\mathrm{SO}_{3} \mathrm{H}\right]^{27}\right)$ cholecystokinin fragment 26-33 amide (CCK8S; Sigma; $20 \mu \mathrm{g} \mathrm{kg}^{-1}, 0.5 \mathrm{~mL} \mathrm{~kg}^{-1}$ in $0.9 \%$ saline), or as vasopressin neurons by transient inhibition or no change in firing rate after CCK8S [59].

Spontaneous spike firing of each neuron was recorded for at least $10 \mathrm{~min}$ before CCK8S administration, and the first $10 \mathrm{~min}$ of each recording was used for analyses of activity patterning; these recordings include the baseline recording periods from neurons that were subsequently challenged with drug administration that have been previously published for other purposes [21,59-62]. For experiments to determine the $\triangle N$-TRPV1 contribution to basal activity, the dialysate was switched to aCSF containing $10 \mathrm{mM}$ of the broad-spectrum TRPV blocker, ruthenium red (Sigma), for $60 \mathrm{~min}$, at least $10 \mathrm{~min}$ after recovery from any effects of IV CCK8S.

\subsection{Hazard Function}

Inter-spike interval histograms were constructed (in $0.01 \mathrm{~s} \mathrm{bins)} \mathrm{for} \mathrm{the} \mathrm{first} 10 \mathrm{~min}$ of recording to generate hazards for each neuron. Hazards were calculated using the formula, hazard $_{[\mathrm{i}-1, \mathrm{i}]}=\mathrm{n}_{[\mathrm{i}-1, \mathrm{i}]} /\left(\mathrm{N}-\mathrm{n}_{[0, \mathrm{i}-1]}\right)$; where hazard ${ }_{[\mathrm{i}-1, \mathrm{i}]}$ is the probability of the next spike firing in a given interval, $i, n_{[i-1, i]}$ is the number of spikes in interval $i, N$ is the total number of spikes in all intervals and $\mathrm{n}_{[0, \mathrm{i}-1]}$ is the total number of spikes in all intervals preceding the current interval, $i$. The peak early hazard was taken as the maximum hazard within the first $0.07 \mathrm{~s}$ after each spike and the mean late hazard was calculated from the $0.41-0.5 \mathrm{~s}$ intervals after each spike. The peak early/mean late hazard ratio (hazard ratio) was then calculated. For presentation in the figures, each inter-spike interval histogram was normalised by dividing each data point in the histogram by the value of the mode for that histogram and each individual hazard was normalised by dividing each data point within the hazard by the peak hazard value of the hazard. The mean normalised inter-spike histogram and hazard was then calculated for each group.

\subsection{Post-Spike Hyperexcitability}

To determine whether individual oxytocin neurons displayed elevated post-spike hyperexcitability within the first $0.07 \mathrm{~s}$ after each spike, we calculated two standard deviations of the mean hazard ratio for oxytocin neurons in non-pregnant rats and added them to the mean hazard ratio of oxytocin neurons in non-pregnant rats to set the threshold to be classified as post-spike hyperexcitability for oxytocin neurons in non-pregnant, late-pregnant, and lactating rats. The same procedure was applied to determine any differences in postspike hyperexcitability for individual vasopressin neurons in non-pregnant, late-pregnant, and lactating rats, using vasopressin neurons from non-pregnant rats as baseline.

\subsection{Coefficient of Variation}

The coefficient of variation of inter-spike interval (CV) was calculated as a measure of variability of spike firing using the formula, $\mathrm{CV}=$ standard deviation/mean. 


\subsection{RNAscope}

$\triangle N-T R P V 1$ mRNA expression was measured in supraoptic nucleus vasopressin neurons using RNAscope. Rats were deeply anaesthetised with pentobarbital (300 $\mathrm{mg} \mathrm{kg}^{-1}$, IP) and perfused with $50 \mathrm{~mL}$ saline followed by $200 \mathrm{~mL} 4 \%$ paraformaldehyde (PFA) in $0.1 \mathrm{M}$ phosphate buffer (PB). Brains were removed, post-fixed overnight in $4 \%$ PFA, transferred to $30 \%$ sucrose solution in $0.1 \mathrm{M} \mathrm{PB}$, and stored at $4{ }^{\circ} \mathrm{C}$ until they were infiltrated with sucrose. Brains were then frozen on dry ice and stored at $-80{ }^{\circ} \mathrm{C}$ until $15 \mu \mathrm{m}$ coronal sections were cut and slide mounted on a cryostat.

Sections were pre-treated according to the Advance Cell Diagnostics, Inc (ACD bio; Hayward, CA, USA) RNAscope Multiplex Fluorescent Assay protocol. Briefly, sections were dehydrated through an ethanol series at room temperature (RT) and air-dried. Endogenous peroxidase activity was blocked with hydrogen peroxide (ACD bio Cat. No. 323100) for $10 \mathrm{~min}$ at RT. Target retrieval was performed in boiling Target Retrieval Reagent (ACD bio Cat. No. 323100) for $5 \mathrm{~min}$. Sections were treated with protease III (ACD bio Cat. No. 323100) for $30 \mathrm{~min}$ at $40^{\circ} \mathrm{C}$ to increase cell permeability.

Dual fluorescent RNAscope was performed using the RNAscope Multiplex Fluorescent Reagent Kit v2 (ACD bio Cat. No. 323,100 and No. 323120) according to the manufacturer's protocol. Briefly, target probes for rat $\triangle \mathrm{N}-\mathrm{TRPV} 1 \mathrm{mRNA}((\mathrm{C} 2 ; 472-1431$ bp, ascension no. NM_031982.1), ACD bio) and rat vasopressin mRNA (C4; 20-525 bp, ascension no. NM_016992.2) were mixed, warmed for $10 \mathrm{~min}$ at $40{ }^{\circ} \mathrm{C}$, and allowed to cool to RT. Sections were subjected to probe hybridisation $\left(2 \mathrm{~h}\right.$ at $\left.40^{\circ} \mathrm{C}\right)$ and amplifier hybridisation (AMP1, AMP2, AMP3; $30 \mathrm{~min}$ at $40^{\circ} \mathrm{C} / \mathrm{AMP}$ ). After washing, $\mathrm{C} 2$ probe signal was developed with HRP-C2 (15 min at $40^{\circ} \mathrm{C}$ ), Opal 570 dye (Akoya Biosciences, Menlo Park, CA, USA; 1:1500; $30 \mathrm{~min}$ at $40^{\circ} \mathrm{C}$ ), followed by horseradish peroxidase blocker $\left(15 \mathrm{~min}\right.$ at $40^{\circ} \mathrm{C}$ ). After further washing, the $\mathrm{C} 4$ probe signal was developed as above but with HRP-C4 and Opal 620 dye (Akoya Biosciences; 1:1500). Slides were coverslipped with ProLong Gold Antifade Mountant (Invitrogen ${ }^{\mathrm{TM}}$; ThermoFisher Scientific, Waltham, MA, USA) and stored at $4{ }^{\circ} \mathrm{C}$.

Sections were imaged in Z-stacks at $570 \mathrm{~nm}$ for $\triangle \mathrm{N}$-TRPV1 $\mathrm{mRNA}$ and $620 \mathrm{~nm}$ for vasopressin mRNA on a confocal microscope (Nikon A1R MP, Tokyo, Japan). Stacks were compressed using ImageJ (National Institutes of Health, Bethesda, MD, USA) Fiji Zprojection Max intensity. Max intensity images were processed using Cell Profiler ${ }^{\mathrm{TM}}$ (Broad Institute, Cambridge, MA, USA) cell image analysis software to create binary threshold images (Figure S1). The area (in pixels) of $\triangle \mathrm{N}-\mathrm{TRPV} 1 \mathrm{mRNA}$ co-localised with vasopressin mRNA was divided by the total area of vasopressin mRNA to provide the percentage of vasopressin mRNA co-labelled with $\triangle \mathrm{N}$-TRPV1 $\mathrm{mRNA}$, and area of $\triangle \mathrm{N}-\mathrm{TRPV} 1 \mathrm{mRNA}$ co-localised with vasopressin mRNA was divided by the total area of $\triangle \mathrm{N}$-TRPV1 mRNA to provide the percentage of $\triangle \mathrm{N}$-TRPV1 mRNA co-labelled with vasopressin mRNA.

\subsection{Statistics}

All values are reported as mean \pm standard error of the mean. Statistical analyses were completed using Sigma Plot version 14 for Windows (Systat Software, San Jose, CA, USA).

\section{Conclusions}

Taken together, the current data suggest that increased intrinsic excitability of oxytocin and vasopressin neurons contribute to normal pregnancy and lactation. Increased postspike hyperexcitability of oxytocin neurons might help underpin burst firing required for delivery of the fetus during birth and milk ejection during suckling, while increased intrinsic osmosensitivity of vasopressin neurons resets the osmotic set-point for vasopressin secretion to drive blood volume expansion during pregnancy.

Supplementary Materials: The following are available online at https:/ / www.mdpi.com/article / $10.3390 /$ ijms22137140/s1, Figure S1. Example of the analysis of vasopressin mRNA and $\Delta N-T R P V 1$ mRNA expression in the supraoptic nucleus of non-pregnant and late-pregnant rats. Figure S2. 
(A-C) Mean ( \pm SEM) peak early, mean late and hazard ratio for phasic vasopressin neurons across reproduction. Figure S3. (A-C) Coefficient of variation of oxytocin neurons, vasopressin neurons and phasic vasopressin neurons.

Author Contributions: R.A.A. and C.H.B. designed the electrophysiology study. M.R.P., A.J.S. and C.H.B. completed the electrophysiology experiments and analyses. G.T.B. and C.H.B. designed the RNAscope study. G.T.B., E.F.B. and I.C. completed and analysed the RNAscope experiment. M.F. co-supervised the RNAscope. All authors contributed to the interpretation of the results. M.R.P. and C.H.B. wrote the first draft manuscript, and all authors provided intellectual input for the final version. All authors have read and agreed to the published version of the manuscript.

Funding: This research was funded by project grants from the Marsden Fund of the Royal Society Te Apārangi and the New Zealand Health Research Council (C.H.B.), a University of Otago Research Grant (C.H.B.) and by University of Otago Doctoral Scholarships (M.R.P. and E.F.B.).

Institutional Review Board Statement: The study was conducted according to the guidelines of the Declaration of Helsinki. All experimental procedures were approved by the University of Otago Animal Ethics Committee and were carried out in accordance with the New Zealand Animal Welfare Act (1999) and associated guidelines.

Informed Consent Statement: Not applicable.

Data Availability Statement: The data presented in this study are available on request from the corresponding author. The data are not publicly available due to administrative requirements.

Acknowledgments: We thank Mehwish Abbasi, Zoë Jacquiery, and Victoria Scott for recordings of basal activity in non-pregnant, late-pregnant, and lactating rats.

Conflicts of Interest: The authors declare no conflict of interest.

\section{References}

1. Brown, C.H. Magnocellular neurons and posterior pituitary function. Compr. Physiol. 2016, 6, 1701-1741.

2. Brunton, P.J.; Arunachalam, S.; Russel, J.A. Control of neurohypophysial hormone secretion, blood osmolality and volume in pregnancy. J. Physiol. Pharmacol. 2008, 59 (Suppl. 8), 27-45.

3. Verbalis, J.G. Disorders of body water homeostasis. Best Pract. Res. Clin. Endocrinol. Metab. 2003, 17, 471-503. [CrossRef]

4. Davison, J.M.; Shiells, E.A.; Philips, P.R.; Lindheimer, M.D. Serial evaluation of vasopressin release and thirst in human pregnancy. Role of human chorionic gonadotrophin in the osmoregulatory changes of gestation. J. Clin. Investig. 1988, 81, 798-806. [CrossRef] [PubMed]

5. Durr, J.A.; Stamoutsos, B.; Lindheimer, M.D. Osmoregulation during pregnancy in the rat. Evidence for resetting of the threshold for vasopressin secretion during gestation. J. Clin. Investig. 1981, 68, 337-346. [CrossRef]

6. Forsling, M.L.; Montgomery, H.; Halpin, D.; Windle, R.J.; Treacher, D.F. Daily patterns of secretion of neurohypophysial hormones in man: Effect of age. Exp. Physiol. 1998, 83, 409-418. [CrossRef] [PubMed]

7. Summerlee, A.J. Extracellular recordings from oxytocin neurones during the expulsive phase of birth in unanaesthetized rats. $J$ Physiol. 1981, 321, 1-9. [CrossRef] [PubMed]

8. Summerlee, A.J.; Lincoln, D.W. Electrophysiological recordings from oxytocinergic neurones during suckling in the unanaesthetized lactating rat. J. Endocrinol. 1981, 90, 255-265. [CrossRef] [PubMed]

9. Wakerley, J.B.; Lincoln, D.W. The milk-ejection reflex of the rat: A 20- to 40-fold acceleration in the firing of paraventricular neurones during oxytocin release. J. Endocrinol. 1973, 57, 477-493. [CrossRef]

10. Voisin, D.L.; Bourque, C.W. Integration of sodium and osmosensory signals in vasopressin neurons. Trends Neurosci. 2002, 25, 199-205. [CrossRef]

11. Bourque, C.W. Central mechanisms of osmosensation and systemic osmoregulation. Nat. Rev. Neurosci. 2008, 9, 519-531. [CrossRef] [PubMed]

12. Naeini, R.S.; Witty, M.F.; Seguela, P.; Bourque, C.W. An N-terminal variant of Trpv1 channel is required for osmosensory transduction. Nat. Neurosci. 2006, 9, 93-98. [CrossRef] [PubMed]

13. Oliet, S.H.; Bourque, C.W. Mechanosensitive channels transduce osmosensitivity in supraoptic neurons. Nature 1993, 364, 341-343. [CrossRef]

14. Zhang, Z.; Kindrat, A.N.; Sharif-Naeini, R.; Bourque, C.W. Actin filaments mediate mechanical gating during osmosensory transduction in rat supraoptic nucleus neurons. J. Neurosci. 2007, 27, 4008-4013. [CrossRef] [PubMed]

15. Greffrath, W.; Magerl, W.; Disque-Kaiser, U.; Martin, E.; Reuss, S.; Boehmer, G. Contribution of Ca ${ }^{2+}$-activated $\mathrm{K}^{+}$channels to hyperpolarizing after-potentials and discharge pattern in rat supraoptic neurones. J. Neuroendocrinol. 2004, 16, 577-588. [CrossRef] [PubMed] 
16. Greffrath, W.; Martin, E.; Reuss, S.; Boehmer, G. Components of after-hyperpolarization in magnocellular neurones of the rat supraoptic nucleus in vitro. J. Physiol. 1998, 513 Pt 2, 493-506. [CrossRef] [PubMed]

17. Kirkpatrick, K.; Bourque, C.W. Activity dependence and functional role of the apamin-sensitive $\mathrm{K}^{+}$current in rat supraoptic neurones in vitro. J. Physiol. 1996, 494 Pt 2, 389-398. [CrossRef] [PubMed]

18. Teruyama, R.; Armstrong, W.E. Calcium-dependent fast depolarizing afterpotentials in vasopressin neurons in the rat supraoptic nucleus. J. Neurophysiol. 2007, 98, 2612-2621. [CrossRef]

19. Cobbett, P.; Smithson, K.G.; Hatton, G.I. Immunoreactivity to vasopressin-But not oxytocin-associated neurophysin antiserum in phasic neurons of rat hypothalamic paraventricular nucleus. Brain Res. 1986, 362, 7-16. [CrossRef]

20. Armstrong, W.E.; Smith, B.N.; Tian, M. Electrophysiological characteristics of immunochemically identified rat oxytocin and vasopressin neurones in vitro. J. Physiol. 1994, 475, 115-128. [CrossRef]

21. Augustine, R.A.; Ladyman, S.R.; Bouwer, G.T.; Alyousif, Y.; Sapsford, T.J.; Scott, V.; Kokay, I.C.; Grattan, D.R.; Brown, C.H. Prolactin regulation of oxytocin neurone activity in pregnancy and lactation. J. Physiol. 2017, 595, 3591-3605. [CrossRef] [PubMed]

22. Johnstone, L.E.; Leng, G.; Brown, C.H. Effects of neurotensin on the organisation of activity in supraoptic nucleus cells in virgin and lactating rats. J. Neuroendocrinol. 2004, 16, 605-611. [CrossRef] [PubMed]

23. Brown, C.H.; Scott, V.; Ludwig, M.; Leng, G.; Bourque, C.W. Somatodendritic dynorphin release: Orchestrating activity patterns of vasopressin neurons. Biochem. Soc. Trans. 2007, 35 Pt 5, 1236-1242. [CrossRef]

24. Brown, C.H.; Stern, J.E.; Jackson, K.L.; Bull, P.M.; Leng, G.; Russell, J.A. Morphine withdrawal increases intrinsic excitability of oxytocin neurons in morphine-dependent rats. Eur. J. Neurosci. 2005, 21, 501-512. [CrossRef] [PubMed]

25. Augustine, R.A.; Seymour, A.J.; Campbell, R.E.; Grattan, D.R.; Brown, C.H. Integrative neuro-humoral regulation of oxytocin neuron activity in pregnancy and lactation. J. Neuroendocrinol. 2018, 30, e12569. [CrossRef] [PubMed]

26. Stern, J.E.; Armstrong, W.E. Changes in the electrical properties of supraoptic nucleus oxytocin and vasopressin neurons during lactation. J. Neurosci. 1996, 16, 4861-4871. [CrossRef]

27. Teruyama, R.; Armstrong, W.E. Changes in the active membrane properties of rat supraoptic neurones during pregnancy and lactation. J. Neuroendocrinol. 2002, 14, 933-944. [CrossRef]

28. Brown, C.H.; Bourque, C.W. Mechanisms of rhythmogenesis: Insights from hypothalamic vasopressin neurons. Trends Neurosci. 2006, 29, 108-115. [CrossRef]

29. Sabatier, N.; Brown, C.H.; Ludwig, M.; Leng, G. Phasic spike patterning in rat supraoptic neurones in vivo and in vitro. J. Physiol. 2004, 558, 161-180. [CrossRef]

30. Royo, J.M.; Brown, C.H.; Leng, G.; MacGregor, D.J. Oxytocin neurones: Intrinsic mechanisms governing the regularity of spiking activity. J. Neuroendocrinol. 2016, 28. [CrossRef]

31. Brown, D.; Fontanaud, P.; Moos, F.C. The variability of basal action potential firing is positively correlated with bursting in hypothalamic oxytocin neurones. J. Neuroendocrinol. 2000, 12, 506-520. [CrossRef]

32. Moos, F.; Fontanaud, P.; Mekaouche, M.; Brown, D. Oxytocin neurones are recruited into co-ordinated fluctuations of firing before bursting in the rat. Neuroscience 2004, 125, 391. [CrossRef] [PubMed]

33. Brown, D.; Moos, F. Onset of bursting in oxytocin cells in suckled rats. J. Physiol. 1997, 503 Pt 3, 625-634. [CrossRef]

34. Davison, J.M.; Vallotton, M.B.; Lindheimer, M.D. Plasma osmolality and urinary concentration and dilution during and after pregnancy: Evidence that lateral recumbency inhibits maximal urinary concentrating ability. Br. J. Obstet. Gynaecol. 1981, 88, 472-479. [CrossRef] [PubMed]

35. Weitzman, R.E.; Leake, R.D.; Rubin, R.T.; Fisher, D.A. The effect of nursing on neurohypophyseal hormone and prolactin secretion in human subjects. J. Clin. Endocrinol Metab. 1980, 51, 836-839. [CrossRef] [PubMed]

36. Suzuki, K.; Koizumi, N.; Hirose, H.; Hokao, R.; Takemura, N.; Motoyoshi, S. Changes in plasma arginine vasopressin concentration during lactation in rats. Comp. Med. 2000, 50, 277-280. [PubMed]

37. Koehler, E.M.; McLemore, G.L.; Tang, W.; Summy-Long, J.Y. Osmoregulation of the magnocellular system during pregnancy and lactation. Am. J. Physiol. 1993, 264 Pt 2, R555-R560. [CrossRef]

38. Tkachenko, O.; Shchekochikhin, D.; Schrier, R.W. Hormones and hemodynamics in pregnancy. Int. J. Endocrinol. Metab. 2014, 12, e14098. [CrossRef]

39. Barron, W.M.; Schreiber, J.; Lindheimer, M.D. Effect of ovarian sex steroids on osmoregulation and vasopressin secretion in the rat. Am. J. Physiol. 1986, 250 Pt 1, E352-E361. [CrossRef]

40. Barron, W.M.; Lindheimer, M.D. Osmoregulation in pseudopregnant and prolactin-treated rats: Comparison with normal gestation. Am. J. Physiol. 1988, 254 Pt 2, R478-R484. [CrossRef]

41. Zhao, S.; Malmgren, C.H.; Shanks, R.D.; Sherwood, O.D. Monoclonal antibodies specific for rat relaxin. VIII. Passive immunization with monoclonal antibodies throughout the second half of pregnancy reduces water consumption in rats. Endocrinology 1995, 136, 1892-1897. [CrossRef]

42. Zhao, L.; Roche, P.J.; Gunnersen, J.M.; Hammond, V.E.; Tregear, G.W.; Wintour, E.M.; Beck, F. Mice without a functional relaxin gene are unable to deliver milk to their pups. Endocrinology 1999, 140, 445-453. [CrossRef]

43. Sunn, N.; Egli, M.; Burazin, T.C.; Burns, P.; Colvill, L.; Davern, P.; Denton, D.A.; Oldfield, B.J.; Weisinger, R.S.; Rauch, M.; et al. Circulating relaxin acts on subfornical organ neurons to stimulate water drinking in the rat. Proc. Natl. Acad. Sci. USA 2002, 99, 1701-1706. [CrossRef] [PubMed] 
44. Way, S.A.; Leng, G. Relaxin increases the firing rate of supraoptic neurones and increases oxytocin secretion in the rat. J. Endocrinol. 1992, 132, 149. [CrossRef]

45. Chakfe, Y.; Bourque, C.W. Excitatory peptides and osmotic pressure modulate mechanosensitive cation channels in concert. Nat. Neurosci. 2000, 3, 572-579. [CrossRef]

46. Prager-Khoutorsky, M.; Khoutorsky, A.; Bourque, C.W. Unique interweaved microtubule scaffold mediates osmosensory transduction via physical interaction with TRPV1. Neuron 2014, 83, 866-878. [CrossRef] [PubMed]

47. Leng, G.; Brown, C.H.; Bull, P.M.; Brown, D.; Scullion, S.; Currie, J.; Blackburn-Munro, R.E.; Feng, J.; Onaka, T.; Verbalis, J.G.; et al Responses of magnocellular neurons to osmotic stimulation involves coactivation of excitatory and inhibitory input: An experimental and theoretical analysis. J. Neurosci. 2001, 21, 6967-6977. [CrossRef] [PubMed]

48. Watanabe, H.; Vriens, J.; Prenen, J.; Droogmans, G.; Voets, T.; Nilius, B. Anandamide and arachidonic acid use epoxyeicosatrienoic acids to activate TRPV4 channels. Nature 2003, 424, 434-438. [CrossRef] [PubMed]

49. Chen, S.R.; MacLennan, D.H. Identification of calmodulin-, $\mathrm{Ca}^{2+-}$, and ruthenium red-binding domains in the Ca ${ }^{2+}$ release channel (ryanodine receptor) of rabbit skeletal muscle sarcoplasmic reticulum. J. Biol. Chem. 1994, 269, 22698-22704. [CrossRef]

50. Tang, Y.; Zucker, R.S. Mitochondrial involvement in post-tetanic potentiation of synaptic transmission. Neuron 1997, 18, 483-491. [CrossRef]

51. Li, Z.; Hatton, G.I. $\mathrm{Ca}^{2+}$ release from internal stores: Role in generating depolarizing after-potentials in rat supraoptic neurones. J. Physiol. 1997, 498 Pt 2, 339-350. [CrossRef] [PubMed]

52. Ludwig, M.; Leng, G. Autoinhibition of supraoptic nucleus vasopressin neurons in vivo: A combined retrodialysis/electrophysiological study in rats. Eur. J. Neurosci. 1997, 9, 2532-2540. [CrossRef]

53. Lindheimer, M.D.; Barron, W.M.; Davison, J.M. Osmoregulation of thirst and vasopressin release in pregnancy. Am. J. Physiol. 1989, 257 Pt 2, F159-F169.

54. Nedungadi, T.P.; Carreno, F.R.; Walch, J.D.; Bathina, C.S.; Cunningham, J.T. Region-specific changes in transient receptor potential vanilloid channel expression in the vasopressin magnocellular system in hepatic cirrhosis-induced hyponatraemia. $J$. Neuroendocrinol. 2012, 24, 642-652. [CrossRef]

55. Rutter, A.R.; Ma, Q.P.; Leveridge, M.; Bonnert, T.P. Heteromerization and colocalization of TrpV1 and TrpV2 in mammalian cell lines and rat dorsal root ganglia. Neuroreport 2005, 16, 1735-1739. [CrossRef] [PubMed]

56. Cheng, W.; Yang, F.; Takanishi, C.L.; Zheng, J. Thermosensitive TRPV channel subunits coassemble into heteromeric channels with intermediate conductance and gating properties. J. Gen. Physiol. 2007, 129, 191-207. [CrossRef] [PubMed]

57. Brown, C.H.; Han, S.Y.; Moaddab, M.; Scott, V.; Schwenke, D.O. Peptidergic control of oxytocin and vasopressin neurons and its role in reproductive and hypertension-associated plasticity. In Neurophysiology of Neuroendocrine Neuron; Armstrong, W.E., Tasker, J.G., Eds.; Wiley-Blackwell: Hoboken, NJ, USA, 2014; pp. 65-86.

58. Horn, T.F.W.; Engelmann, M. In vivo microdialysis for nonapeptides in rat brain-A practical guide. Methods 2001, 23, 41-53. [CrossRef] [PubMed]

59. Scott, V.; Bishop, V.R.; Leng, G.; Brown, C.H. Dehydration-induced modulation of kappa-opioid inhibition of vasopressin neurone activity. J. Physiol. 2009, 587, 5679-5689. [CrossRef]

60. Ladyman, S.R.; Augustine, R.A.; Scherf, E.; Phillipps, H.R.; Brown, C.H.; Grattan, D.R. Attenuated hypothalamic responses to alpha-melanocyte stimulating hormone during pregnancy in the rat. J. Physiol. 2016, 594, 1087-1101. [CrossRef]

61. Scott, V.; Brown, C.H. Kisspeptin activation of supraoptic nucleus neurons in vivo. Endocrinology 2011, 152, 3862-3870. [CrossRef]

62. Seymour, A.J.; Scott, V.; Augustine, R.A.; Bouwer, G.T.; Campbell, R.E.; Brown, C.H. Development of an excitatory kisspeptin projection to the oxytocin system in late pregnancy. J. Physiol. 2017, 595, 825-838. [CrossRef] [PubMed] 